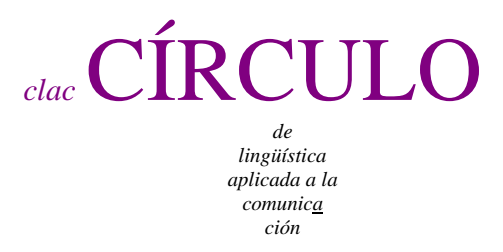

$60 / 2014$

\title{
A FORMAL THEORY CAN EXPLAIN DISJUNCTIVE ILLUSORY INFERENCES
}

\author{
Miguel López Astorga \\ Talca University \\ milopez at utalca cl
}

\begin{abstract}
There are disjunctive inferences that can be considered to be illusory, since, when faced to them, people tend to draw logically incorrect conclusions. The mental models theory can explain this problem by distinguishing between mental models and fully explicit models. According to it, individuals often derive only conclusions compatible with the mental models, and not with the fully explicit models. However, I try to show in this paper that a syntactic approach can also account for the problem of the mentioned inferences. It is enough to assume that disjunctions are basically inclusive and that exclusive disjunctions require resorting to more complex formulae.
\end{abstract}

Key words: disjunction, illusory inferences, mental logic, mental models

López Astorga, Miguel. 2014.

A formal theory can explain disjunctive illusory inferences.

Círculo de Lingüística Aplicada a la Comunicación 60, 122-143.

http://www.ucm.es/info/circulo/no60/lopez.pdf

http://revistas.ucm.es/index.php/CLAC

DOI: http://dx.doi.org/10.5209/rev_CLAC.2014.v60.47445

(C) 2014 Miguel López Astorga

CÍRCULO de Lingüística Aplicada a la Comunicación (clac)

Universidad Complutense de Madrid. ISSN 1576-4737. http://www.ucm.es/info/circulo 


\section{Contents}

1. Introduction, 123

2. The problem of the disjunctive illusory inferences, 125

3. The mental models theory and disjunctions, 126

4. The mental models theory and the disjunctive illusory inferences, 128

5. Standard propositional calculus and the problem of the mints, the gumballs, and the lollipops, 131

6. Standard propositional calculus and the problem of the blue, red, and orange candies, 134

7. The disjunctive illusory inferences and the mental logic theory, 137

References, 140

\section{Introduction}

The problem of the disjunctive illusory inferences refers to inferences with an exclusive disjunction embedded in other exclusive disjunction from which individuals usually deduce logically invalid conclusions ${ }^{1}$. A representative example of this kind of inference can be the following:

"You have the bread, or else you have the soup or else the salad" (Khemlani \& Johnson-Laird, 2009, p. 617).

The particularity of the inferences of this type is that, if the first disjunct ('you have the bread') is assumed to be true, people tend to draw that it is not possible that you have the soup and you have the salad. Nevertheless, as shown below, it is incorrect because, following standard propositional logic, this proposition enables the three disjuncts to be true at the same time.

\footnotetext{
${ }^{1}$ This paper has been made with the support of the Ministry of Education of the Government of Chile (Ministerio de Educación del Gobierno de Chile) through the Program MECE Higher Education (MECE Educación Superior). The author would like to thank the mentioned Ministry and Program for their help in funding this paper.
} 
The mental models theory (e.g., Byrne \& Johnson-Laird, 2009; Johnson-Laird, 1983, 2001, 2006, 2010, 2012; Johnson-Laird \& Byrne, 2002; Johnson-Laird, Byrne, \& Girotto, 2009; Khemlani \& Johnson-Laird, 2009; Oakhill \& Garnham, 1996; Orenes \& Johnson-Laird, 2012) explains and even predicts individuals' majority answer to disjunctive illusory inferences. This fact can lead us to think that the mental models theory is the only valid theory of reasoning that can account for this phenomenon. In fact, some proponents of it state that other theories cannot do so. In their opinion,

"No other current theory of reasoning, whether based on formal rules of inference (e.g., Braine \& O’Brien, 1998a²; Rips, 1994) or on the probability calculus (Oaksford \& Chater, 2001), predicts the illusions or the remedial effects of instructions to think about truth and falsity. These theories could introduce fallacious rules in order to predict the illusions, but the resulting system is likely to be inconsistent and, in consequence, to predict other sorts of fallacy that do not occur” (Khemlani \& Johnson-Laird, 2009, p. 623).

Certainly, the mental models theory not only explains people's response to inferences with a structure such as that described, but also predicts what kind of additional instructions can improve the results. I will not question this point in this paper. It is absolutely true that the mental models theory can explain this problem. My goal is to show that other alternative type of theories that is explicitly mentioned by Khemlani and Johnson-Laird (2009) in the previous quote, the formal rules theories, can also account for the facts related to the disjunctive illusory inferences. Indeed, as it will be shown below, a syntactic approach can explain both the conclusions that individuals often derive from these inferences and the improvement that the additional instructions used by Khemlani and Johnson-Laird (2009) provide. Only one important point needs to be recalled in this way: standard propositional calculus considers disjunctions to be inclusive and the disjunctions of the illusory inferences are exclusive.

Thus, I will begin by describing in details the problem of the disjunctive illusory inferences and why their logically valid conclusion is not that preferred by people. Secondly, after commenting several general theses of the mental models theory, I will

\footnotetext{
${ }^{2}$ In Khemlani \& Johnson-Laird's (2009) original text, it is written 'Braine and O’Brien, 1998'. I have added 'a' following ' 1998 ' because I will quote bellow a chapter of that same book as a different work.
} 
show how this theory explains and predicts both the conclusion that is almost always deduced by people in this kind of inference and the effects of certain additional data in it. Then, I will argue that a formal approach can also account for that conclusion and those effects. Finally, I will analyze the possibility that my explanation is compatible with the theses of formal theories such as the mental logic theory (e.g., Braine \& O’Brien, 1998a).

\section{The problem of the disjunctive illusory inferences}

If the previous example referring to the bread, the soup, and the salad is taken into account, and it is assumed that ' $\mathrm{V}$ ' stands for the logical exclusive disjunction, it can be said that the logical form of its first premise is as follows:

\section{$\mathrm{p} \underline{\mathrm{V}}(\mathrm{q} \underline{\mathrm{V}} \mathrm{r})$}

Where 'p' represents 'you have the bread', ' $q$ ' refers to 'you have the soup', and ' $r$ ' means 'you have the salad'.

In this way, the second premise would be the disjunct assumed to be true, i.e.:

\section{p}

As mentioned, faced to this scenario, people tend to draw the conclusion that you cannot have the soup and the salad. In other words, if ' $\neg$ ' is considered to be the logical denial, individuals usually deduce $\neg q$ and $\neg$. This is not correct in standard logic because that logic allows $p$ to be true, $q \underline{\mathrm{V}} \mathrm{r}$ to be false, and $\mathrm{q}$ and $\mathrm{r}$ to be true at the same time. In can be checked in Table 1

Table 1. Truth table of $\mathrm{p} \underline{\mathrm{V}}(\mathrm{q} \underline{\mathrm{V}} \mathrm{r})$

\begin{tabular}{|l|l|l|l|l|}
\hline $\mathrm{p}$ & $\mathrm{q}$ & $\mathrm{r}$ & $\mathrm{q} \underline{\mathrm{V} r}$ & $\mathrm{p} \underline{\mathrm{V}}(\mathrm{q} \underline{\mathrm{V}} \mathrm{r})$ \\
\hline 1 & 1 & 1 & 0 & 1 \\
1 & 1 & 0 & 1 & 0 \\
1 & 0 & 1 & 1 & 0 \\
1 & 0 & 0 & 0 & 1 \\
0 & 1 & 1 & 0 & 0 \\
0 & 1 & 0 & 1 & 1 \\
0 & 0 & 1 & 1 & 1 \\
0 & 0 & 0 & 0 & 0 \\
\hline
\end{tabular}


In Table 1, ' 1 ' stands for 'true' and '0' represents 'false', and, as it can be seen in it, there is a case in which, while $p$ is true and $q \underline{V} r$ is false, $p \underline{V}(q \underline{V} r), q$, and $r$ are true. As it is well known, according to standard logic, an exclusive disjunction is true when a disjunct is true and the other disjunct is false. Otherwise (when the two disjuncts are true or the two disjuncts are false), the logical exclusive disjunction is false. Thus, the relevant case here is that corresponding to the first row. If we assume that ' $v$ ' refers to the truth-value of the formula following between brackets, it can be stated that,

$$
\begin{aligned}
& \text { If } v(p)=1, v(q)=1 \text {, and } v(r)=1 \text {, then } v(q \underline{V} r)=0 \text {. However, if } v(p)=1 \text { and } \\
& v(q \underline{V} r)=0 \text {, then } v[p \underline{V}(q \underline{\mathrm{V}} r)]=1 \text {. }
\end{aligned}
$$

Therefore, it is possible that, in the example considered, you have the bread, the soup, and the salad at the same time.

This circumstance can lead one to think that human mind does not follow the requirements of standard logic. Nevertheless, in that case, it seems necessary an alternative framework that can account for this problem. Undoubtedly, the mental models theory gives us such a framework.

\section{The mental models theory and disjunctions}

As far as the problem of disjunctive illusory inferences is concerned, there are two relevant aspects of the mental models theory that need to be considered. Firstly, this theory claims that human reasoning is a basically semantic process in which the possibilities or models of propositions are identified and combined. Thus, only the models referring to cases in which both the premises and the conclusion are true are taken into account. Secondly, the models always represent situations in which the proposition is true, and there are models that can be easily detected and models that require additional effort to be identified. The models that can be easily detected are called 'mental models' and the models that require effort are denominated 'fully explicit models'. In this way, the mental models of a proposition such as $\mathrm{p} \underline{\mathrm{V}} \mathrm{q}$ are simply: 
q

Nonetheless, the fully explicit models of this same proposition are the following:

$$
\begin{aligned}
& \mathrm{p} \text { and } \neg \mathrm{q} \\
& \neg \mathrm{p} \text { and } \mathrm{q}
\end{aligned}
$$

This distinction between mental models and fully explicit models is always important, but it is especially relevant in the case of the disjunctive illusory inferences. In such inferences, as mentioned, there is an exclusive disjunction included in other exclusive disjunction and, obviously, this circumstance has an influence on the models. In this way, the mental models of a proposition such as $\mathrm{p} \underline{\mathrm{V}}(\mathrm{q} \underline{\mathrm{V}} \mathrm{r})$ are these ones:

\section{$\mathrm{p}$ \\ $\mathrm{q}$ \\ $\mathrm{r}$}

However, its fully explicit models are:

$$
\begin{aligned}
& \mathrm{p} \text { and } \mathrm{q} \text { and } \mathrm{r} \\
& \mathrm{p} \text { and } \neg \mathrm{q} \text { and } \neg \mathrm{r} \\
& \neg \mathrm{p} \text { and } \mathrm{q} \text { and } \neg \mathrm{r} \\
& \neg \mathrm{p} \text { and } \neg \mathrm{q} \text { and } \mathrm{r}
\end{aligned}
$$

As it can be seen in Table 1, these four models refer to the four cases in which v[p $\underline{\mathrm{V}}$ (q $\underline{\mathrm{V}} \mathrm{r})]=1$ (first, fourth, sixth, and seventh rows). Nevertheless, it is important to indicate that the mental models theory does not state that human beings reason following the truth tables of standard logic. On the one hand, as said, it is possible that individuals only pay attention to the mental models, and not to the fully explicit models. On the other hand, there are also modulation mechanisms, which can block certain models because of the meaning or the context of a proposition or because of pragmatic factors. Nonetheless, as regards the issue of this paper, it is only relevant that it is possible that individuals only consider the mental models of a proposition. In fact, this is exactly what Khemlani and Johnson-Laird (2009) argue for the disjunctive illusory inferences. In their opinion, the differentiation between mental models and fully explicit models not 
only explains the usual conclusion that people draw from such inferences and the effects that certain information added to the premises can have, but also predicts them. These strengths of the mental models theory are shown in the next part.

4. The mental models theory and the disjunctive illusory inferences

Khemlani and Johnson-Laird (2009) carry out several experiments related to the disjunctive illusory inferences. I will not analyze all of them here because it can be superfluous and trivial. This is because some of their more controversial experimental conditions are representative enough and, if it is explained how the mental models theory accounts for them, it is obvious and evident how that same theory can account for the other experimental conditions. For this reason, I will focus only on the disjunctive illusory inferences used by Khemlani and Johnson-Laird (2009) that can be more illustrative.

One of such inferences is as follows:

"Suppose that only one of the following assertions is true:

(1) You have the mints.

(2) You have the gumballs or the lollipops, but not both.

Also, supposes you have the mints. What, if anything, follows? Is it possible that you also have either the gumballs or the lollipops? Could you have both?” (Khemlani \& Johnson-Laird, 2009, p. 618).

As indicated, the fully explicit models show that it is possible to have the mints, the gumballs, and the lollipops at the same time. Nevertheless, the mental models theory predicts that, faced to this task, most individuals will respond that you cannot have the three candies, since they will only consider these mental models:

mints

gumballs

lollipops 
Certainly, their experimental results will support their explanation and their prediction, since their participants tended to answer that the three candies could not be had at the same time.

Other interesting experimental condition was this one:

"Suppose that one of the following assertions is true and one is false.

(1) You have the blue candies and the red candies.

(2) You have the red candies or else the orange candies, but not both" (Khemlani \& Johnson-Laird, 2009, p. 619).

As stated by Khemlani and Johnson-Laird (2009), the mental models are now:

blue candies and red candies

red candies

orange candies

Therefore, in their view, individuals should tend to respond 'no' to this question:

"Is it possible to have only the blue candies and the orange candies?" (Khemlani \& Johnson-Laird, 2009, p. 619).

Indeed, most their participants answered negatively to the question. However, the correct response is 'yes'. This fact is demonstrated by the fully explicit models, which are these ones:

blue candies and red candies and orange candies

$\neg$ (blue candies) and red candies and $\neg$ (orange candies)

blue candies and $\neg$ (red candies) and orange candies

$\neg$ (blue candies) and $\neg$ (red candies) and orange candies

The third model -blue candies and $\neg$ (red candies) and orange candies- makes clear that the blue candies and the orange candies can be had at the same time. Nevertheless, as said, according to Khemlani and Johnson-Laird (2009), people respond negatively because they only consider the mental models. 
A little change in this last condition also showed, in their view, that their approach is correct. The final question was removed and instead this one was included:

“Is it possible to have only red candies?” (Khemlani \& Johnson-Laird, 2009, p. 619).

Khemlani and Johnson-Laird (2009) predict that their participants will answer 'yes' to this question. The reason is not, in their opinion, that the second fully explicit model $\neg$ (blue candies) and red candies and $\neg$ (orange candies)- enables a situation in which the red candies are the only candies that are had. The reason is the fact that the second mental model -red candies- directly refers to that scenario. In any case, their participants' responses were coherent with their prediction, since they tended to respond that it was possible to have red candies and not to have blue candies and orange candies. But other interesting point of Khemlani and Johnson-Laird's (2009) experiments was that, in some conditions with the first version of the problem of the candies, i.e., the version in which it is asked whether or not it is possible a scenario with only the blue and orange candies, additional instruction were given. In particular, the participants were asked to review their response, and it was explicitly mentioned that they should confirm whether they had considered facts such as that only one premise was correct. This additional information improved the results and Khemlani and Johnson-Laird (2009) seem to interpret that the cause is that the additional information can lead one to take the fully explicit models into account.

Finally, in other condition, the additional instructions consisted of a definition. This can be observed in the following example:

“An entrée consists of one meat and one vegetable course. Suppose that one of the following assertions is true and one is false.

(1) One course is meat, and one course is salad.

(2) One course is salad, or else one course is vegetables.

Is an entrée possible?” (Khemlani \& Johnson-Laird, 2009, p. 621).

As it can be noted, the formal structure of this version is the same as that of the first version of the problem of the candies. Nevertheless, what is important in it is that it also 
improved the results. The explanation of this fact given by Khemlani and Johnson-Laird (2009) is that the initial definition leaded the participants to think about the fully explicit models.

As mentioned, Khemlani and Johnson-Laird's (2009) experiments include more experimental conditions. However, the described conditions are illustrative enough because it is obvious how the arguments commented in this section can be applied to the other conditions that I have not taken into account. In this way, what is relevant for this paper is that Khemlani and Johnson-Laird's (2009) participants gave responses contrary to classical formal logic in the first two problems to which I have referred (the problem of the mints, the gumballs, and the lollipops, and the first version of the problem of the blue, red, and orange candies). It is true that the results were positive in the second version of the blue, red, and orange candies (i.e., the version corresponding to the question about the red candies) and that they significantly improved in the problems with additional instructions (both when such instructions asked to review the response and when they included a definition), but the mental models theory provides a framework that explains and predicts all these facts. Nevertheless, as indicated, I will try to prove that a syntactic approach based on formal rules can also account for these phenomena.

5. Standard propositional calculus and the problem of the mints, the gumballs, and the lollipops

Really, there are several theories that try to explain human reasoning from a syntactic or formal perspective. As indicated, Khemlani and Johnson-Laird (2009) explicitly quote two very representative theories of this kind: Rips (1994) and Braine and O'Brien (1998a). However, I will not assume any of those theories in particular here. My aim is only to demonstrate that the difficulties linked to the disjunctive illusory inferences do not prove that human mind does not follow basic logical principles or requirements. For this reason, just as a hypothesis for this paper, I will suppose that human reasoning works following the syntactic rules of standard propositional calculus and that it coherent with frames such as that exposed by Gentzen (1934). I am aware that a hypothesis of this type is controversial and hard to accept, since the literature on clac 60/2014, 122-143 
cognitive science reveals that people do not seem to use some basic rules of standard propositional calculus, and that, because of this, some formal approaches do not admit all the rules of that calculus. This is the case, for example, of the mental logic theory described by Braine and O’Brien (1998).

Nevertheless, I am assuming here the general hypothesis that standard logic leads human inferential activity because I want to show that any formal framework could, in principle, account for the problems of the disjunctive illusory inferences. Furthermore, I will also show below that the explanations that I will propose in this paper are not necessarily incompatible with approaches such as that of the mental logic theory.

Thus, to analyze the disjunctive illusory inferences from standard propositional calculus, a first point needs to be considered. That calculus only has formal rules for inclusive disjunctions, not for exclusive disjunctions. This is an important point because, although standard propositional calculus has the means to work with exclusive disjunctions, this kind of disjunctions is not basic in that calculus, and it can be thought that the root of the problem is this one.

Certainly, individuals' mistake in the task of the mints, the gumballs, and the lollipops appears to be that they do not deny its second exclusive disjunction ( $\mathrm{q} \underline{\mathrm{V}} \mathrm{r}$ ) correctly, and that they tend to deny that disjunction as they deny inclusive disjunctions. If we assume that ' $\mathrm{V}$ ' stands for inclusive disjunction, it can be said that, while $\mathrm{v}(\mathrm{p} \underline{\mathrm{V}} \mathrm{q})=0$ both when $\mathrm{v}(\mathrm{p})=1$ and $\mathrm{v}(\mathrm{q})=1$ and when $\mathrm{v}(\mathrm{p})=0$ and $\mathrm{v}(\mathrm{q})=0, \mathrm{v}(\mathrm{p} \mathrm{V} \mathrm{q})=0$ only when $\mathrm{v}(\mathrm{p})=0$ and $\mathrm{v}(\mathrm{q})=0$ (see Table 2 ).

Table 2. Truth tables of exclusive and inclusive disjunction

\begin{tabular}{|l|l|l|l|}
\hline $\mathrm{p}$ & $\mathrm{q}$ & $\mathrm{p} \underline{\mathrm{V} q}$ & $\mathrm{p} \mathrm{V} \mathrm{q}$ \\
\hline 1 & 1 & 0 & 1 \\
1 & 0 & 1 & 1 \\
0 & 1 & 1 & 1 \\
0 & 0 & 0 & 0 \\
\hline
\end{tabular}

Nevertheless, although the disjunction 'you have the gumballs or the lollipops' is exclusive in the mentioned problem, because Khemlani and Johnson-Laird's most 
participants respond that it is not possible to have the gumballs and the lollipops at the same time, it seems that they deny that disjunction as if it were inclusive. Therefore, if it is assumed that human mind works using formal rules, it is necessary to explain why this fact occurs.

A possible account can be found in the way standard propositional calculus enables to consider exclusive disjunctions. In that calculus, an inclusive disjunction can be transformed into an exclusive disjunction by means of an additional formula, and such an additional formula can be, if we assume that ' $\&$ ' is the logical conjunction, for example:

$$
\neg(\mathrm{p} \& \mathrm{q})
$$

Indeed, a new formula can be built by supposing that the formulae p V q and $\neg$ (p \& q) are two conjuncts linked by ' $\&$ ':

$$
(p \vee q) \& \neg(p \& q)
$$

As shown in Table 3, the truth-values of this last formula are the same as those of exclusive disjunction. It hence is an adequate formula for expressing exclusive disjunction in standard propositional calculus.

Table 3. Truth-values of (p V q) \& $\neg(p \& q)$ and $p \underline{V} q$

\begin{tabular}{|l|l|l|l|l|l|l|}
\hline $\mathrm{p}$ & $\mathrm{q}$ & $\mathrm{p} V \mathrm{q}$ & $\mathrm{p} \& \mathrm{q}$ & $\neg(\mathrm{p} \& \mathrm{q})$ & $(\mathrm{p} V \mathrm{q}) \& \neg(\mathrm{p} \& \mathrm{q})$ & $\mathrm{p} \underline{\mathrm{V} q}$ \\
\hline 1 & 1 & 1 & 1 & 0 & 0 & 0 \\
1 & 0 & 1 & 0 & 1 & 1 & 1 \\
0 & 1 & 1 & 0 & 1 & 1 & 1 \\
0 & 0 & 0 & 0 & 1 & 0 & 0 \\
\hline
\end{tabular}

However, the difficulty of the problem of the mints, the gumballs, and the lollipops is that includes three propositional variables. That problem allows establishing the following equivalences:

p: 'you have the mints'.

q: 'you have the gumballs'.

r: 'you have the lollipops'.

In this way, it can be thought that individuals tend to formalize it as follows: 


\section{A: $[p \mathrm{~V}(\mathrm{q} V \mathrm{r})] \& \neg[\mathrm{p} \&(\mathrm{q} V \mathrm{r})] \& \neg(\mathrm{q} V \mathrm{r})$}

In $\mathrm{A}$, the second conjunct $-\neg[\mathrm{p} \&(\mathrm{q} \mathrm{V} \mathrm{r})]$ - transforms p V (q V r) into an exclusive disjunction and the third conjunct $-\neg(\mathrm{q} \& \mathrm{r})$ - transforms $\mathrm{q} V \mathrm{~V}$ into an exclusive disjunction. If $\mathrm{A}$ is assumed as a logical form that contains the information transmitted, this derivation can be made:

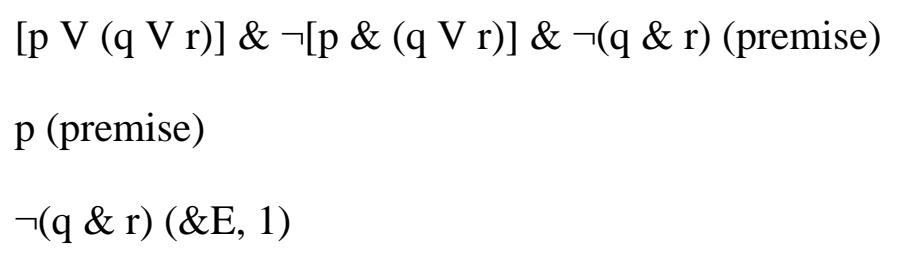

Where step 2 is the assumption that 'you have the mints' and ' $\& E$ ' refers to a basic logical rule that holds in standard propositional calculus: the conjunction elimination rule (x \& y; ergo x).

As it can be noted, only an inferential step (step 3) is needed to draw the conclusion that you do not have the gumballs and the lollipops.

Nonetheless, if the disjunctions p V (q V r) and q V r are exclusive, why is it possible to deduce this conclusion (recall that $q \underline{\mathrm{V}} \mathrm{r}$ is also false when both $\mathrm{q}$ and $\mathrm{r}$ are true)? It is not hard to respond to this question. Individuals assuming A do not note that $\neg$ (q \& r) is not just a conjunct, but also an essential part of the formula $\mathrm{q} \mathrm{V} r$ when interpreted as exclusive. In this way, the real logical form of the problem is not A, but B.

$$
\text { B: }\{\mathrm{p} V[(\mathrm{q} V \mathrm{r}) \& \neg(\mathrm{q} \& \mathrm{r})]\} \& \neg\{\mathrm{p} \&[(\mathrm{q} V \mathrm{r}) \& \neg(\mathrm{q} \& \mathrm{r})]\}
$$

This is the mistake that individuals often make in problems such as that of mints, the gumballs, and the lollipops. The mistake, given that $\mathrm{B}$ is a formula really difficult and complex, and that working memory and human intellectual abilities and skills are limited, is absolutely understandable, possible, and plausible. And, in addition, it clearly explains why khemlani and Johnson-Laird's (2009) participants responded, in problems with this structure, that the cases of $q \&$ r could not be true. 
6. Standard propositional calculus and the problem of the blue, red, and orange candies

If we continue to accepting the arguments of the previous section, it can be said that individuals tend to consider that the logical form of the problem of the blue, red, and orange candies is this one:

$$
\text { C: }[(p \& q) V(q V r)] \& \neg[(p \& q) \&(q V r)] \& \neg(q \& r)
$$

Where the equivalences are these ones:

p: 'you have the blue candies'.

q: 'you have the red candies'.

r: 'you have the orange candies'.

Obviously, in C, the second conjunct - $\neg[(p \&$ \&) \& (q V r)]- transforms (p \& q) V (q V r) into a exclusive disjunction. $\neg(\mathrm{q} \& \mathrm{r}$ ) in turn transforms $\mathrm{q} V \mathrm{r}$ into an exclusive disjunction.

The difficulties of this problem are two. On the one hand, it does not enable to clearly deduce the response to the question of its first version, that is, whether or not you can have both the blue candies and the orange candies. On the other hand, the possible derivation requires many steps, and it can be thought that the more steps are required in an inference, the greater will be the complexity of that inference for individuals. Certainly, the derivation corresponding to the first version could be as follows:
(1) $[(p \&$ q) V (q V r)] \& $\neg[(p \&$ q) \& (q V r)] \& $\neg(q \&$ r) (premise)
(2) p \& q (assumption)
(3) q (\&E, 2)
(4) Steps 2-3 are eliminated
(5) q V r (assumption)
(6) r (assumption)
(7) ᄀ(q \& r) $(\& E, 1)$
(8) $\neg \mathrm{q}(\mathrm{MPT}, 6,7)$
(9) $\neg[(p \& q) \&(q V r)](\& E, 1)$ 
(10) $\neg(p \&$ q) (MPT, 5, 9)

(11) ...

Where 'MPT' is Chrysippus' modus ponendo tollens [ $\neg(\mathrm{x} \& \mathrm{y})$, x; ergo $\neg \mathrm{y}$ ], a rule that also holds in standard propositional calculus.

Given that there is not second premise, it can be thought that individuals begin assuming the possibility of p \& q being true (step 2). Nonetheless, this assumption leads to q (step 3), i.e., to a scenario in which it is not possible only p and r. Step 4 hence consists of noting that, if $\mathrm{v}(\mathrm{p} \& \mathrm{q})=1$, then it is not possible that $\mathrm{v}(\mathrm{p})=1, \mathrm{v}(\mathrm{r})=1, \mathrm{v}(\mathrm{q})$ $=0$. The second possibility is to assume $\mathrm{q}$ V r (step 5). Thus, two new possibilities are opened now: $\mathrm{q}$ and $\mathrm{r}$. The possibility of q cannot be taken into account, since, again, if $\mathrm{q}$ is true, it is not possible a scenario with $\mathrm{p}, \mathrm{r}$, and $\neg \mathrm{q}$. Therefore, the next step is directly to suppose r (step 6), but r only leads to $\neg q$ (step 8) and $\neg$ (p \& q) (step 10), which means that it does not enable to deduce $\mathrm{p}$.

Evidently, $\mathrm{p}$ is possible in a scenario in which $\mathrm{v}(\mathrm{r})=1$-and hence $\mathrm{v}(\mathrm{q} \mathrm{v} \mathrm{r})=1$ - because, although it is true that $\mathrm{p}$ cannot be drawn, it is also true that $r$ does not necessarily lead to $\neg$ p. Nonetheless, because many steps are required (and individuals can stop the derivation before completing it) and it is not possible to obtain $\mathrm{p}$ in a direct way in the scenarios that can be supposed, it is obvious that individuals can tend to respond that $\mathrm{p}$ and $r$ cannot be true at the same time, which explains the majority answer in Khemlani and Johnson-Laird's (2009) experiment.

The case in which the possibility of the red candies (q) is asked is different. As it can be checked in the previous deduction, it is very easy to note that q is possible, since step 3 already indicates it. Furthermore, it can also be supposed that, in the condition in which additional instructions were presented, the indication to review and check whether or not the meanings of the propositions had been correctly understood could lead Khemlani and Johnson-Laird's participants to realize that the fact that $\mathrm{p}$ cannot be derived does not imply that $\mathrm{p}$ is false (at least until $\neg \mathrm{p}$ is drawn). And this circumstance could be the cause of the improvement in participants' responses. Likewise, something similar could happen in the problem of the entrée, which had the same structure as that of the blue, red, and orange candies. The definition of the entrée (p \& r) could help the 
participants to note that, if $\neg \mathrm{p}$ has not been deduced, it cannot be said that $\mathrm{p}$ is false or impossible.

Therefore the previous arguments show that formal or syntactic approaches can explain, and even predict, most individuals' responses in reasoning tasks referring to the disjunctive illusory inferences, and that the mental models theory is not the only framework that can do it. Nevertheless, as mentioned, the literature on cognitive science proves that a frame exclusively based on standard propositional calculus is hard to accept. I will address this issue in the next section.

\section{Disjunctive illusory inferences and the mental logic theory}

Indeed, the literature shows that, in several experiments involving simple logical rules holding in standard propositional calculus, people tend to respond incorrectly, This fact can lead one to assume that, because it seems that the mental models theory does not have those problems, and this last theory can explain most cognitive phenomena, the mental models theory is the only valid theory. However, the findings of the literature need to be qualified and understood.

It is true that several experimental results (e.g., those of Orenes and Johnson-Laird, 2012) reveal us that certain basic logical rules -such as, for example, the conditional introduction rule ( $\mathrm{x}$; ergo $\mathrm{x}->\mathrm{y}$, where ' $->$ ' is the logical conditional) or the disjunction introduction rule (x; ergo x V y) are not often applied by people. Nevertheless, neither of those problematic rules is used in the previous deductions. In my view, it is possible to assume a formal framework and, at the same time, to claim that human beings do not usually apply all the rules of standard propositional calculus. It is possible even to think that some persons, for any reason, are more likely to use certain rules. In this way, to assume a syntactic approach does not mean to suppose that human mind is like a computer that only applies logical rules in automatic and mechanical way. A formal theory can also admit that not all the inferences made by human beings are rational or logical, and that many everyday conclusions that people draw are caused by the action of heuristics or biases. A syntactic approach can hence be compatible with theories such as the dual-process theory (e.g., Evans, 2008; Reyna, 2004; Stanovich, 1999, 2004, 
2012), which distinguishes different systems or processes in human mind, and raises that reasoning includes both heuristic and biased activities and analytical and logical inferences.

The mental logic theory is particularly interesting in this way, since, in addition to holding ideas consistent with those of the precedent paragraph (O’Brien, 1998), it only accepts the formal rules of standard propositional calculus that, according to empirical data, people really use. Thus, this theory is based on experimental results and does not admit any rule of classical logic that is not supported by empirical findings. The result is a powerful theory whose fundamental theses are consistent with many experimental data reported by the literature on cognitive science. Although this theory does not accept that human reasoning works in accordance with truth tables and I have resorted to tables of that kind in my arguments, I suspect that a possible explanation of the disjunctive illusory inferences offered from the mental logic theory would not be incompatible with that proposed by me in this paper. I will indicate why.

Mental logic, as said, is not standard propositional calculus (other important point in this regard is that the mental logic theory does not admit the material interpretation of conditional), but I think that the aspects of classical logic that the mental logic theory rejects are not included in my account. At least in its version exposed by Braine and O'Brien (1998b), the mental logic theory does not seem to distinguish between exclusive and inclusive disjunctions. This theory states that there is a connection between pragmatics and the logical rules of reasoning (Braine \& O’Brien, 1998c), but, in my view, it would not be hard to admit, from its framework, that exclusive disjunction can be expressed by means of the formula (p V q) \& $\neg(p \& q)$. On the other hand, what is most important is that, in my formal demonstrations, I have only used two rules, \&E and MPT, which are included in the set of rules accepted by the mental logic theory. In particular \&E corresponds to the schema 9 proposed by Braine and O’Brien (1998b) and they consider it to be a 'Feeder Schema' (that is, a schema that is applied when it is needed). Likewise, Braine and O'Brien (1998b) think that MPT is a 'Core Schema' (that is a schema that people apply every time they can do it) and it corresponds to their schema number 4 . 
For these reasons, from my point of view, although to assume that standard propositional calculus leads human reasoning is problematic and controversial, my arguments can be accepted, since they appear to be coherent with other theories based on formal rules that do not admit all the rules and requirements of classical logic. After all, the idea that human inferential activity follows standard propositional calculus has only been a hypothesis in this paper.

\section{Conclusions}

It seems that both the mental models theory and a syntactic approach based on formal logic can account for the problem of the disjunctive illusory inferences. This fact is not really unusual, since, as shown, for example, by López Astorga (2013), there are other cognitive phenomena that can be explained both from the semantic framework of the mental models theory and from formal theories. Thus, it could be thought that each of these two approaches refers to a different way of expressing the same facts, or, in other words, that each of these two approaches explain the same facts using a different language.

However, to assume this last idea does not appear to be appropriate. From a psychological point of view, the mental models theory and the syntactic frameworks describe different processes, which means that both approaches cannot be admitted at the same time. So, it seems that a decisive or crucial experiment is needed for identifying some phenomenon that can be explained by the mental models theory and that a formal theory cannot account for (or vice versa). It is true that, in many cases, as, for example, in this paper, the explanations from a formal framework are post hoc. However, the formal rules theories also raise their predictions and check them by means of experiments. In fact, as it can be seen in works such as that of Braine and O'Brien (1998a), the predictions of the mental logic theory are often confirmed. Thus, although it must be acknowledged that the mental models theory can predict and explain human intellectual activities in most cases, the idea that formal theories can also do it cannot be absolutely rejected. 
The issue that the syntactic approaches need to clarify is that related to the formalization. It is well known that natural language expressions do not always directly refer to the same logical operators. The context and the meaning of the expressions can lead one to attribute different logical operators to a same proposition in different scenarios. This is not a new problem and the disjunctive illusory inferences are not the inferences that show it for the first time. Therefore, a difficulty that the formal rules theories need to solve is that related to the exact procedures by which natural language expressions are translated into logical forms. In the particular case of the disjunctive illusory inferences, I have proposed that an adequate form for exclusive disjunction is ( $\mathrm{p}$ V q) \& $\neg(p \& q)$, but maybe it is necessary to describe a more rigorous and systematic procedure. In this way, it can be said that my logical form of exclusive disjunctions is only one of the possible forms that can be thought. Other form could be, for example, ( $p$ $\mathrm{V}$ q) \& $[(\mathrm{p}->\neg \mathrm{q})$ \& (q -> $\neg \mathrm{p})]$. This problem hence requires further empirical research. It is obvious that to find an algorithm that allows us to identify whether a disjunction is inclusive or exclusive is a very hard task (perhaps an impossible task), but to propose a more or less systematic procedure for that does seem an easier and possible task. Be that as it may, it seems that this procedure is not necessary just in the case of inclusive and exclusive disjunctions, but also in that of other controversial logical operators, for example, conditional.

Nevertheless, an even more important matter that should be more explored is that referring to the mechanisms that improve individuals' conclusions when they face to disjunctive illusory inferences. Khemlani and Johnson-Laird's (2009) experiments show that they obtain better conclusions when the additional instruction of reviewing their responses or a definition are included, but it continues to be unclear exactly how that additional instruction or that definition can improve the results. In this way, a detailed description of the process by which those elements influence individuals' answers is also required. It is needed to indicate under what conditions and circumstances the results can be better and under what conditions and circumstances the results can be worse. And this problem is more important than the previous ones because the mental models theory must also solve it. 
References

Braine, M. D. S. \& O’Brien, D. P. (Eds.) (1998a). Mental Logic. Mahwah, NJ: Lawrence Erlbaum Associates, Inc., Publishers.

Braine, M. D. S. \& O’Brien, D. P. (1998b). The theory of mental-propositional logic: Description and illustration. In M. D. S. Braine \& D. P. O’Brien (Eds.), Mental Logic (pp. 79-89). Mahwah, NJ: Lawrence Erlbaum Associates, Inc., Publishers.

Braine, M. D. S. \& O’Brien, D. P. (1998c). How to investigate mental logic and the syntax of thought. In M. D. S. Braine \& D. P. O’Brien (Eds.), Mental Logic (pp. 45-61). Mahwah, NJ: Lawrence Erlbaum Associates, Inc., Publishers.

Byrne, R. M. J. \& Johnson-Laird, P. N. (2009). 'If' and the problems of conditional reasoning. Trends in Cognitive Science, 13, 282-287.

Evans, J. St. B. T. (2008). Dual-processing accounts of reasoning, judgment, and social cognition. Annual Review of Psychology, 59, 255-278.

Gentzen, G. (1934). Untersuchungen über das logische. I. Mathematische Zeitschrift, 39, 176-210.

Johnson-Laird, P. N. (1983). Mental Models. Towards a Cognitive Science on Language, Inference, and Consciousness. Cambridge, MA: Harvard University Press.

Johnson-Laird, P. N. (2001). Mental models and deduction. Trends in Cognitive Science, 5, 434-442.

Johnson-Laird, P. N. (2006). How We Reason. Oxford, UK: Oxford University Press.

Johnson-Laird, P. N. (2010). Against logical form. Psychologica Belgica, 5(3\&4), 193221.

Johnson-Laird, P. N. (2012). Inference with mental models. In K. J. Holyoak \& R. G. Morrison (Eds.), The Oxford Handbook of Thinking and Reasoning (pp. 134-145). New York, NY: Oxford University Press.

Johnson-Laird, P. N. \& Byrne, R. M. J. (2002). Conditionals: A theory of meaning, pragmatics, and inference. Psychological Review, 109, 646-678. 
Johnson-Laird, P. N., Byrne, R. M. J., \& Girotto, V. (2009). The mental models theory of conditionals: A reply to Guy Politzer. Topoi, 28, 78-80.

Khemlani, S. \& Johnson-Laird, P. N. (2009). Disjunctive illusory inferences and how to eliminate them. Memory \& Cognition, 37(5), 615-623.

López Astorga, M. (2013). Are conditional and disjunction really comparable? Universum, 28(2), 229-242.

Oakhill, J. \& Garnham, A. (Eds.), (1996). Mental Models in Cognitive Science. Essays in Honour of Phil Johnson-Laird. Hove, UK: Psychology Press.

Oaksford, M. \& Chater, N. (2001). The probabilistic approach to human reasoning. Trends in Cognitive Science, 5, 349-357.

O’Brien, D. P. (1998). Mental logic and irrationality: We can put a man on the moon so why can't we solve those logical reasoning problems? In M. D. S. Braine \& D. P. O’Brien (Eds.), Mental Logic (pp. 23-43). Mahwah, NJ: Lawrence Erlbaum Associates, Inc., Publishers.

Orenes, I. \& Johnson-Laird, P. N. (2012). Logic, models, and paradoxical inferences. Mind \& Language, 27(4), 357-377.

Reyna, V. F. (2004). How people make decisions that involve risk: A dual-process approach. Current Directions in Psychology Science, 13, 60-66.

Rips, L. J. (1994). The Psychology of Proof: Deductive Reasoning in Human Thinking. Cambridge, MA: Massachusetts Institute of Technology (MIT) Press.

Stanovich, K. E. (1999). Who is Rational? Studies of Individual Differences in Reasoning. Mahwah, NJ: Erlbaum.

Stanovich, K. E. (2004). The Robot's Rebellion: Finding Meaning in the Age of Darwin. Chicago, IL: Chicago University Press.

Stanovich, K. E. (2012). On the distinction between rationality and intelligence for understanding individual differences in reasoning. In K. Holyoak \& R. Morrison (Eds.), The Oxford Handbook of Thinking and Reasoning (pp. 343-365). New York: NY: Oxford University Press. 
López Astorga: disjunctive illusory inferences 143

Received: July 31, 2014

Accepted: December 4, 2014

Revised: December 4, 2014

Published: December 4, 2014

clac 60/2014, 122-143 